\title{
DETECTION OF C-TYPE NATRIURETIC PEPTIDE (CNP) TRANSCRIPT IN THE RAT HEART AND IMMUNE ORGANS
}

\author{
Angelika M. Vollmar, Alexander L. Gerbes ${ }^{1,2}$, Mona Nemer ${ }^{2}$, and Rüdiger Schulz
}

\begin{abstract}
Institute of Pharmacology, Toxicology and Pharmacy, University of Munich, Kögiginstr. 16, 8000 Munich 22, Germany, 'Department of Medicine II, Klinikum Grosshadern, University of Munich, and 2Clinical Research Institute of Montreal, Montreal, Canada.
\end{abstract}

SUMMARY: Previous studies suggested the expression of mRNA, coding for CNP, exclusively in the central nervous system. In the present study, using the polymerase chain reaction (PCR) technique instead of the less sensitive Northern blot hybridization, CNP-specific sequences have also been detected in rat atria and ventricles of the heart as well as in organs of the immune system (thymus, spleen and lymph nodes). Parallel PCR-assays documented ANP-mRNA in these tissues. To verify specificity of the PCR-products, Southern blots have been hybridized with a third internal oligonucleotide and amplicification products have been sequenced. The relative level of CNP-mRNA in these tissues was estimated to be in the range of $1-9 \%$ of total brain CNP transcripts. The results suggest that the peptide may have a peripheral as well as a central site of action. In light of its pronounced effect on cell proliferation, particular interest should focus on a possible role of CNP in the immune system.

\section{INTRODUCTION}

C-type natriuretic peptide (CNP), a new member of the natriuretic peptide family (1), shows features distinct from ANP and BNP, as CNP-mRNA expression has been restricted to the central nervous system (2). Furthermore, CNP selectively binds to the B-subtype of natriuretic peptide receptors which was reported to be mainly expressed in the brain (3). Accordingly, a centrai site of action for this peptide has been suggested $(2,3)$

Recently, however, by means of the PCR-technique the Btype receptor transcript has been detected in the periphery $(4,5)$, proposing the presence of the corresponding ligand CNP, as well as a functional role of this peptide in peripheral organs. Indeed, a most recent report communicates the presence of CNP in cultured endothelial cells (6).

The aim of the present study was to investigate the expression of mRNA coding for CNP in peripheral tissues by use of the highly sensitive PCR-technique. Emphasis was put on cardiac tissues, which are known to be the main site of synthesis for ANP and BNP, and on organs of the immune system, knowing that ANP, a member of the natriuretic peptides, is expressed in certain immunocompetent cells $(7,8)$

\section{MATERIALS AND METHODS}

mRNA extraction: Total RNA from rat tissues (Sprague Dawley, male, $100-120 \mathrm{~g}, \mathrm{n}=3$ ) was extracted using the guanidinium thiocyanate- $\mathrm{CsCl}_{2}$ technique. The integrity of the RNA preparation was assessed by gel electrophoresis. and MRNA was isolated subsequently by use of a kit (PolyATtract, Promega, FRG). mRNA was estimated by UV adsorbance and additionally quantified by dot blot hybridization to end-labelled $p(\mathrm{dT}) 12-18$ according to (9).

cDNA synthesis: $1 \mathrm{mg}$ mRNA was employed for reverse transcriptase reaction, using $\mathrm{p}(\mathrm{dT}) 12-18$ and avian myeloblastosis virus reverse transcriptase (Promega, RT. system kit).
PCR amplification of ANP- and CNP transcripts: PCR for ANP was conducted as previosly described (9). Briefly, various amounts of CDNA were added to $700 \mathrm{ng}$ each of sense primer (5'-CAGCATGGGCTCCTTCTCCA-3') and antisense primer (5'-GTCAATCCTACCCCCGAAGCAGCT3') corresponding to the first and second exon of the rat ANP gene (10). $25-40$ cycles of PCR amplification, using 2.5 units of Taq DNA polymerase (Boehringer, Mannheim, FRG), were performed. Amplification products (430 bp) were separated by gel electrophoresis (2.5\% agarose), stained by ethidium bromide, visualized under UV and blotted to nylon membranes (Hybond-N, Amersham, FRG). An end-labelled oligonucleotide ( ${ }^{3}{ }^{32} \mathrm{P}-$ ATP $5000 \mathrm{\omega Ci} / \mathrm{mmol}$, T4-polynucleotide kinase) corresponding to coding sequences located between the two PCA primers (5'-CTGCTAGACCACCTGGAGGAG-3') was used for hybridization.

Amplification and identification of CNP sequences were conducted as decribed for ANP, except for the use of the primers (700ng, each): a sense (5'CGCACCATGCACC'TCTCCCAGCTGAT-3') and an antisense primer ( $5^{\prime}$-CGCTGCACTAACATCCCAGACCGC-3') corresponding to sequences in the first and second exon of the rat CNP gene (2) were used. The 553 bp comprising CNP amplification products were analysed as described above. For hybridization, a noncoding primer located in the second exon (5'-ATGGAGCCGATCCGGTCCAGCTT-3') was employed.

Three different mRNA samples of each tissue were employed and PCR amplification of each sample was conducted at least twice. For both amplification procedures and each tissue sample various initial amounts of cDNA templates and numbers of PCR cycles were tested to ensure exponential amplification of the fragments of interest.

Semiquantification of PCR-products: Estimation of CNP- as well as ANP-mRNA tissue levels was conducted by densitometry of the corresponding hybridization bands (11). The values for either brain (CNP)- or atria (ANP) amplification products were assigned to an arbitrary unit of 100. Densitometry values are presented as percentage. 
Sequencing of CNP-transcripts: PCR products from the various tissues were sequenced directly on an automated system using Taq DNA polymerase and fluorescence labelled dideoxynucleotides. Sequencing was done at least once in each direction as described (12).

\section{RESULTS}

\section{Amplification of CNP-sequences in the heart and immune} organs

CDNA samples corresponding to $0.5-50 \mathrm{ng}$ total mRNA from ventricular and atrial tissues were subjected to 30 PCR cycles. Rat genomic DNA as well as CDNA from rat brain were employed as positive controls for the expected 824 bp and 554 bp comprising amplification products. CDNA (50 ng mRNA) from liver, which has been reported to express neither ANP nor BNP (9) and omission of CDNA, respectively, were employed to control for nonspecific amplification. To further support the CNP-specificity of the PCR-products, Southerp blots were carried out by hybridization with a 32 -P-end-labelled oligonucleotide, which corresponds to a CDNA sequence located between the two PCR-primers. As shown in Fig. 1A, ventricular and atrial tissues express CNP-sequences comigrating with the CNP-amplification product from brain. Moreover, cDNA (corresponding to 2.5-50 ng mRNA) from thymus, spleen and lymph nodes also yield the CNP-specific 554 bp amplification product. For comparison, Fig. 1B shows the expression of ANP-mRNA in the corresponding RNA samples. As expected, atria and ventricles show strong signals for the ANP transcript (430 bp). ANP-mRNA was also detected in the brain and the immune organs confirming previous reports $(7,8,13-15)$.

$\begin{array}{lllllllllllllll}1 & 2 & 3 & 4 & 5 & 6 & 7 & 8 & 9 & 10 & 11 & 12 & 13 & 14 & 15\end{array}$

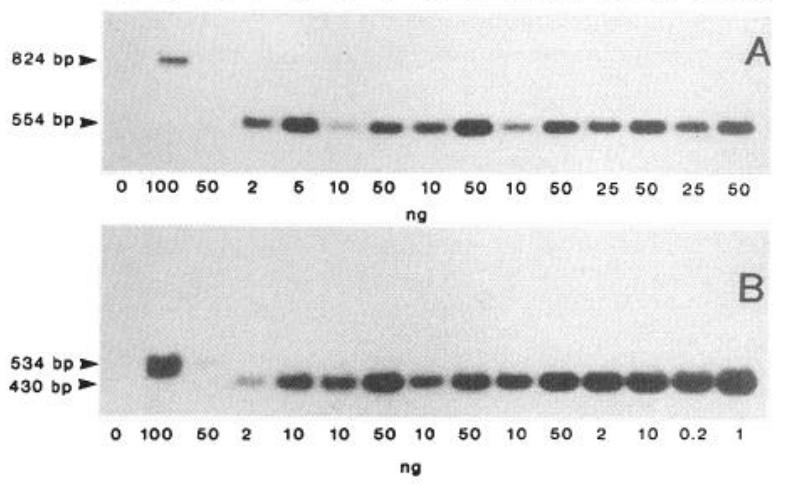

Fiqure 1: Representative Southern blot of CNP-PCR products (A) and ANP-PCR products (B). Various amounts of poly(A) ${ }^{+}$RNAs (ng) were amplified by PCR (30 cycles) and analysed as described in Materials and Methods. Lanes: 1 , no cDNA; 2 , rat genomic DNA; 3 , liver; $4+5$, brain; $6+7$, thymus; $8+9$ lymph node, $10+11$, spleen; $12+13$, ventricle; $14+15$, atria.
Sequencing of CNP-amplification products To verify the CNP-specificity of the amplification products, an aliquot thereof was sequenced using the same set of primers (12). The sequence was virtually identical to the corresponding DNA sequence of the rat CNP-gene (2) (data not shown).

Relative quantification of $\mathrm{PCR}$ amplification products

The densitometric evaluation of the CNP amplification products is presented as percentage of the brain value (Fig. 2). The signal for CNP mRNA is clearly strongest in the brain, confirming the predominant central expression of the peptide $(1,2)$. However, atria and ventricle also contain CNP-specific PCR-products in the range of 5-9\% of the brain. CNP-products of the thymus, spleen and lymph nodes amount to approximately $1-5 \%$ of that of the brain (Fig. 2).

In contrast, it is well known that ANP is mainly synthesized in the heart atria and to a substantial amount in the ventricles (i.e. approximately $6 \%$ of the atrial PCR transcripts). The amount of PCR-generated ANPsequences in the brain and the lymphoid organs were estimated to range between $0.02 \%$ and $1 \%$ of the atrial products (data not shown).

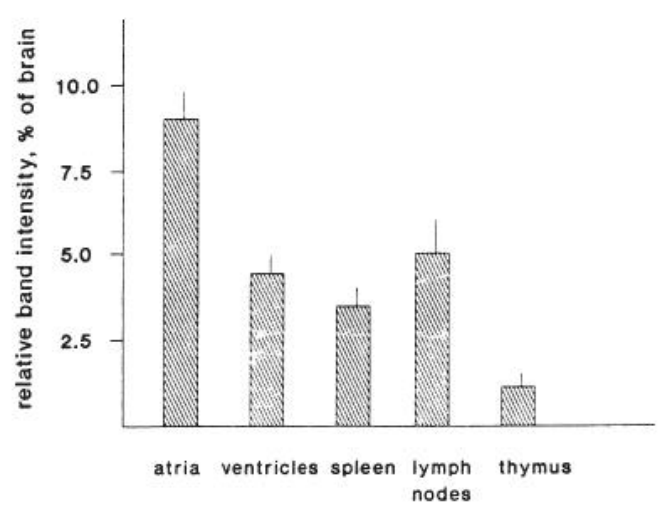

Figure 2: Relative quantification of CNP-mRNA in various tissues. The values for each organ are expressed as percentage of the brain value and represent the mean $( \pm$ SEM) of three independent mRNA preparations of each organ and two PCR runs.

\section{DISCUSSION}

CNP-specific mRNA in mammals has been detected in the central nervous system. Thus, CNP was originally thought to represent the brain form of the natriuretic peptide family (1-3).

However, we report here CNP-specific amplification products in peripheral tissues, such as the heart atria and ventricles as well as in organs of the immune system, using the highly sensitive PCR technique. The PCR products have been sequenced in order to verify the corresponding sequence of the CNP-gene $(2,12)$. Semiquantitative comparison of CNP-expression in these tissues reveal that atrial and ventricular mRNA coding for CNP ranges between $5-9 \%$ of that in the brain. PCR products in thymus, spleen and lymph nodes amount to approximately $1-5 \%$ of those obtained from the brain. Thus, our data confirm the predominant central expression of CNP, but provide strong evidence that CNP-mRNA is not restricted to the CNS, as originally proposed (1-3). 
The presence of CNP-mRNA in peripheral tissues has actually been postulated before $(4,5)$, but failed to be detected by conventional MRNA analysis $(2,16)$. This proposal was based on various experimental findings, such as the CNP-specific B-receptor. This receptor, initially believed to be confined to the central nervous system (3), has also been found in the periphery by means of PCR analysis as well as by autoradiographic visualisation $(4,5$, 17). Secondly, small amounts of immunoreactive CNP-like peptide were found by radioimmunoassay in the kidney and intestine (18), and most recently also in cultured epithelial cells (6). No material was reported for other peripheral tissues including the heart ventricles (18).

Based on the predominant central site of synthesis of CNP, as compared to ANP/BNP, the peptide was suggested to act as a neurotransmitter or neuromodulator rather than a cardiac hormone (1-5, 19). Pharmacological actions distinct from those of ANP and BNP have been proposed for CNP, as it has been shown to stimulate water intake in rats contrasting the action of ANP (19)

Our data, however, suggest that the action of CNP is not confined to the central nervous system. With respect to the presence of CNP production in the immune system, particular interest should be focused on its pronounced antimitogenic and antiproliferative effect, initially observed in cultered smooth muscle cells (20). CNP may function in the regulation of cell proliferation within the immune system. The peptide may constitute a further substance shared by the neuroendocrine- and the immune system supporting the notion of a functional interaction between both systems (21).

\section{ACKNOWLEDGMENT}

We are grateful to Ms. U.Rüberg and C. Siegl for excellent technical assistance. Ms. Dr. B. Obermeier (Laboratory of Molecular Biology, University of Munich) is thanked for performing the sequencing. This work was supported by an Asche grant of the Deutsche Gesellschaft für Verdauungs- und Stoffwechselkrankheiten (A.L.G.), by the Medical Research Council and the National Science and Engineering Council of Canada (M.N.) and by the Deutsche Forschungsgemeinschaft (R.S.).

\section{REFERENCES}

1. Sudoh T, Minamino N, Kangawa K, Matsuo H 1990 A new member of natriuretic family identified in porcine brain. Biochem Biophys Res Commun 168: 863-870

2. Kojima M, Minamino N, Kangawa K, Matsuo H 1990 Cloning and sequencing of a CDNA encoding a precursor for rat C-type natriuretic peptide (CNP). FEBS Lett 276 : 209-213

3. Koller K, Lowe DG, Bennett GL, Minamino N, Kangawa K, Matsuo H, Goeddel, DV 1991 Selective activation of the B natriuretic peptide receptor by $\mathrm{C}$-type natriuretic peptide (CNP). Science 252: 120-123

4. Canaan-KühI S, Jamison RL, Myers BD, Pratt RE 1992 Identification of " $\mathrm{B}$ " receptor for natriuretic peptide in human kidney. Enciocrinology 130: 550-552

5. Ohyama $Y$, Miyamoto K, Saito $Y$, Minamino N, Kangawa K, Matsuo H 1992 Cloning and characterization of two forms of C-type natriuretic peptide receptor in rat brain. Biochem Biophys Res Commun 183: 743-749
6. Suga $S$, Nakao $K$, Itoh $H$, Komatsu $Y$, Ogawa $Y$, Hama $N$, Imura $H 1992$ Endothelial production of C-type natriuretic peptide and its marked augmentation by transforming growth factor- $\beta$. Possible existence of "vascular natriuretic system". J Clin Invest 90: 1145-1149

7. Volimar AM, Colbatzky F, Schulz R 1992 Increased production of atrial natriuretic peptide in the rat thymus after irradiation. Immunopharmacology in press

8. Trosby $M$, Lee D, Huang W, Yang $Z$, Copolov DL, Lim AT 1991 Evidence for atrial natriuretic peptide- (5-28) production by macrophages of the rat spleen: an immunochemical and nonradioactive in situ hybridization approach. Endocrinology 129: 991-1000

9. Dagnino L, Drouin J, Nemer M 1991 Differential expression of natriuretic peptide genes in cardiac and extracardiac tissues. Mol Endocrinol 5: 1292-1300

10. Argentin S, Nemer M, Drouin J, Scott GK, Kennedy BP, Davies PL 1985 The gene for rat atrial natriuretic peptide. $J$ Biol Chem 260: 4568-4571

11. Terada $Y$, Moriyama $T$, Martin BM, Knepper MA Garcia-Perez A 1991 RT-PCR microlocalization of mRNA for guanylyl cyclase-coupled ANF receptor in rat kidney. Am J Physiol 261: F1080-1087

12. Bauer PH, Müller S, Puzicha M, Pippig S, Obermaier B, Helmreich EJM Lohse MJ 1992 Phosducin is a protein kinase A-regulated G-protein regulator. Nature 358: 73-76

13. Gutkowska J, Nemer M 1989 Structure, expression and function of atrial natriuretic peptide in extraatrial tissue. Endocr Rev 10: 519-136

14. Vollmar AM, Schulz R 1990 Atrial natriuretic peptide is synthesized in the human thymus. Endocrinology 126: 2277-2280

15. Vollmar AM, Schulz R 1990 Dexamethasone action on rat thymic atrial natriuretic peptide. Endocrinology 127: 3240-3242

16. Takahashi T, Allen PD, Izumo S 1992 Expression of A-, $B-$, and C-type natriuretic peptide genes in failing and developing human ventricles. Circ Res 71: 9-17

17. Konrad EM, Thibault G, Schiffrin EL 1992 Autoradiographic visualization of the natriuretic peptide receptor-B in rat tissues. Reg Peptides 39: 177-189

18. Komatsu $Y$, Nakao K, Suga S, Ogawa $Y$, Mukoyama $M$, Arai $H$, Shirakami G, Hosoda K, Nakagawa O, Hama N, Kishimoto I, Imura H 1991 C-type natriuretic peptide (CNP) in rats and humans. Endocrinology 129: 1104-1106

19. Samson, WK, Skala KD, Huang FLS 1991 CNP-22 stimulates, rather than inhibits, water drinking in the rat: evidence for a unique biological action of the C-type natriuretic peptides. Brain Res 568: 285-288

20. Furuya M, Yosida M, Hayashi Y, Ohnuma N, Minamino $\mathrm{N}$, Kangawa K, Matsuo $\mathrm{H} 1991 \mathrm{C}$-type natriuretic peptide is a growth inhibitor of rat vascular smooth muscle cells. Biochem Biophys Res Commun 177: 927-931

21. Blalock, JE 1989 A molecular basis for bidirectional communication between the immune and neuroendocrine systems. Physiol Rev 69: 1-32 